\title{
DESCRIPTION OF TWO NEW OTACILIA SPECIES FROM ANHUI, CHINA (ARANEAE, PHRUROLITHIDAE)
}

\author{
Lina Fu ${ }^{1}$, Zhisheng Zhang ${ }^{2}$ and Feng Zhang ${ }^{1 *}$ \\ ${ }^{1}$ The Key Laboratory of Invertebrate Systematics and Application, College of Life Sciences \\ Hebei University, Baoding, Hebei 071002, P. R. China \\ ${ }^{2}$ Key Laboratory of Eco-environments in Three Gorges Reservoir Region (Ministry of Education) \\ School of Life Science, Southwest University, Chongqing 400715, China \\ ${ }^{*}$ Corresponding author: dudu06042001@163.com
}

The present paper reports two new Otacilia species from Huangshan, Anhui, China: Otacilia obesa sp. n. and O. macrospora sp. n.

Key words: spider, taxonomy, China.

\section{INTRODUCTION}

Phrurolithidae Banks 1892, raised to family status by RAMírez (2014) in agreement with Deeleman-Reinhold (2001), currently consists of 14 genera and 188 species (World Spider Catalog 2015). The Phrurolithidae are hunting spiders living in leaf litter, especially bamboo leaves, woody debris or on the forest floor.

Otacilia Thorell, 1897, one of the most species-rich genera of the sac spider family Phrurolithidae (World Spider Catalog 2015), is widely distributed in Southeast Asia and East Asia. Presently, 39 Otacilia species have been reported in the world. This genus can be recognized by the following characteristics: a relatively broad opisthosomal scutum (less than half of the opisthosoma) in most males; one or two strong anterior bristles on chelicerae; several prolateral spines (most often four) on femur I; six to ten retroventral or proventral spines on tibia I; a femoral ventral apophysis with a depression retrolaterally on male palp; one or two RTA with different sizes; weakly sclerotized bulb and relatively short embolus; epigyne generally with a median plate and vulva with pairs of transparent bursae and spermathecae (JÄGER \& WundERLICH 2012).

While examining the collections from Huangshan, Anhui, China, we found some Otacilia specimens which are different from the currently known Otacilia species. They are identified as two new species: O. obesa sp. n. and $O$. macrospora sp. n. 


\section{MATERIAL AND METHODS}

The terminology follows Hu and ZHANG (2011) and JäGER and WUNDERLICH (2012). All measurements given in the text are in millimeters. Carapace length was measured from the anterior margin to the rear margin of the carapace medially. Eye sizes were measured as the maximum diameter in dorsal or frontal view. Leg measurements are shown as: total length (femur, patella, tibia, metatarsus, tarsus). Total length is the sum of the carapace and abdomen lengths, regardless of the petiolus. Epigynes were removed and cleared in a warm solution of $10 \%$ potassium hydroxide, transferred to alcohol and temporarily mounted for drawing. All specimens are preserved in $75 \%$ alcohol and were examined, drawn and measured under a Leica M205A stereomicroscope equipped with an Abbe drawing device. Photographs were taken using a Leica M205A stereomicroscope equipped with a DFC450 CCD. The specimens are deposited in the Museum of Hebei University, Baoding, China (MHBU).

The following abbreviations are used: AER, anterior eye row; ALE, anterior lateral eyes; $\mathrm{AME}$, anterior median eyes; $\mathrm{BU}$, bursae; $\mathrm{CD}$, copulatory duct; $\mathrm{CO}$, copulatory openings; E, embolus; FA, femoral apophysis; FD, fertilization ducts; MOA, median ocular area; MP, median plate; PER, posterior eye row; PLE, posterior lateral eyes; PME, posterior median eyes; PMS, posterior median spinnerets; RTA, retrolateral tibial apophysis; SD, sperm duct; SP, spermathecae; TA, tegular apophysis.

\section{TAXONOMY}

\section{Otacilia obesa sp. n.}

$$
\text { (Figs 1-13) }
$$

Type material. Holotype male, China, Anhui Province, Huangshan City, Xiuning County, Qiyun Mountain $\left(2^{\circ} 48.269^{\prime} \mathrm{N}, 118^{\circ} 02.298^{\prime} \mathrm{E}\right), 22$ October 2013, Luyu Wang leg. Paratypes: 18 males and 18 females, same data as holotype; 7 males and 2 females, Qiyun Mountain, Dongtianfudi $\left(29^{\circ} 48.427^{\prime} \mathrm{N}, 118^{\circ} 02.457^{\prime} \mathrm{E}\right), 22$ October 2013, Luyu Wang leg.; 6 males and 5 females, Qimen County, Gu'niujiang $\left(30^{\circ} 01.080^{\prime} \mathrm{N}, 117^{\circ} 31.780^{\prime} \mathrm{E}\right), 23$ October 2013, Luyu Wang leg.

Etymology. The species name comes from the Latin word 'obesus', meaning 'obese', referring to the round bulb of the male palp.

Diagnosis. The new species is characterized by the following combination of characters: dark body color and markings; round bulb, hook-shaped embolus, long and sharp tegular apophysis; basally wide and apically pointed RTA; presence of a small depression retrolaterally on femoral apophysis in the male; rectangular and long epigynal median plate; small copulatory openings; and oval, anteriorly transparent bursae in the female.

Description - Male (Fig. 1). Total length 2.91-3.09 ( $\mathrm{n}=8$ ). Holotype body 3.03 long; carapace 1.49 long, 1.26 wide; abdomen 1.44 long, 0.86 wide. Carapace oval, narrow anteriorly; yellowish, with broad median grey stripe; thoracic part higher than the cephalic part; fovea longitudinal, distinct. In dorsal view, AER slightly recurved, PER slightly wider 
than AER and almost straight. Diameter of eyes: AME 0.06, ALE 0.08, PME 0.07, PLE 0.08. Interdistances of eyes: AME-AME 0.05, AME-ALE 0.02, PME-PME 0.09, PME-PLE 0.06. MOA 0.23 long, front 0.18 wide, back 0.25 wide. Clypeus 0.10 high. Chelicerae with one or two strong anterior bristles; cheliceral promargin with three well-separated teeth and retromargin with five clustered denticles. Labium slightly wider than long. Legs light brown. Leg measurements: leg I 5.41 (1.48, 0.22, 1.76, 1.31, 0.64), II 4.48 (1.21, 0.39, 1.23, 1.04, 0.61), III 3.86 (1.05, 0.44, 0.86, 1.05, 0.46), IV 5.50 (1.70, 0.31, 1.15, 1.52, 0.82). Leg formula: 4123. Femora I-IV basally with one dorsal spine. Femora I with four prolateral spines and femora II with two prolateral spines; tibiae I with eight proventral spines and nine retroventral spines, tibiae II with eight proventral spines and seven retroventral spines; metatarsi I with four pairs of ventral spines, metatarsi II with four proventral spines and three retroventral spines. Abdomen grey; anterior part with a U-shaped dorsal scutum, almost occupying $1 / 2$ length and $2 / 3$ width of the whole abdomen; posterior part dark brown, with several chevron-like stripes dorsally.

Palp (Figs 3-6, 9-11). Palpal femur with an subdistal apophysis and a retrolateral concavity; tibia with a large, posteriorly extending RTA consisting of a broad base and a fingershaped tip; distal cymbium ventrally with a row of setae; tegulum convex, TA long and thin, extending beyond margin of tegulum; embolus hook-shaped, slightly sharp apically.

Female (Fig. 2). Total length 3.02-3.49 ( $\mathrm{n}=7$ ). One paratype from Qiyunshan Mountain: body 3.21 long; carapace 1.41 long, 1.30 wide; abdomen 1.62 long, 1.15 wide. Carapace light brown, oval, abruptly narrow anteriorly. Diameter of eyes: AME 0.06, ALE 0.08, PME 0.07, PLE 0.08. Eye interdistances: AME-AME 0.06, AME-ALE 0.03, PME-PME 0.11, PMEPLE 0.06. MOA 0.24 long, front 0.18 wide, back 0.26 wide. Clypeus 0.08 high. Chelicerae light brown. Labium and gnathocoxae brown. Legs and palps yellowish brown. Leg measurements: I 5.52 (1.57, 0.32, 1.76, 1.41, 0.46), II 4.43 (1.32, 0.37, 1.22, 0.96, 0.56), III 3.82 (1.05, $0.36,0.86,0.98,0.57)$, IV 5.89 (1.63, 0.47, 1.44, 1.59, 0.76). Leg formula: 4123. Femora I-IV basally with one dorsal spine. Femora I with five (left) and three (right) prolateral spines, and femora II with three prolateral spines; tibiae I with nine pairs of ventral spines, tibiae II with eight pairs of ventral spines; metatarsi I and II with the same spination as male. Abdomen without dorsal scutum. Other characters as in male.

Epigyne (Figs 7-8, 12-13): median plate rectangular, longer than wide, with parallel lateral margin. Copulatory openings small, oval, situated medially on epigyne (Figs 7, 12). Vulva anteriorly with a pair of large transparent egg-shaped bursae, posteriorly with a pair of thick, closely situated spermathecae; copulatory ducts relatively long.

Distribution. China (Anhui).

Remarks. The new species resembles several Chinese Otacilia species, but it differs from O. komurai (Yaginuma, 1952) by: long and sharp tegular apophysis (shorter in the latter), and parallel bursae (diverging relatively in the latter). It can be separated from O. foveata (Song, 1990) and O. liupan Hu et Zhang, 2011 by: parallel lateral margin of epigynal median plate (not parallel in O. foveata and O. liupan), and large bursae (smaller bursae in the latter). It also can be distinguished from O. jianfengling Fu, Zhang et Zhu, 2010 and $O$. fujiana $\mathrm{Fu}$, Jin et Zhang, 2014 by: narrow median plate (broader in the latter), and RTA with a wide base and pointed tip (a curve tip in the latter).

This new species can be easily distinguished from other Otacilia species, such as, it differs from O. armatissima Thorell, 1897 (type species of the Otacilia 


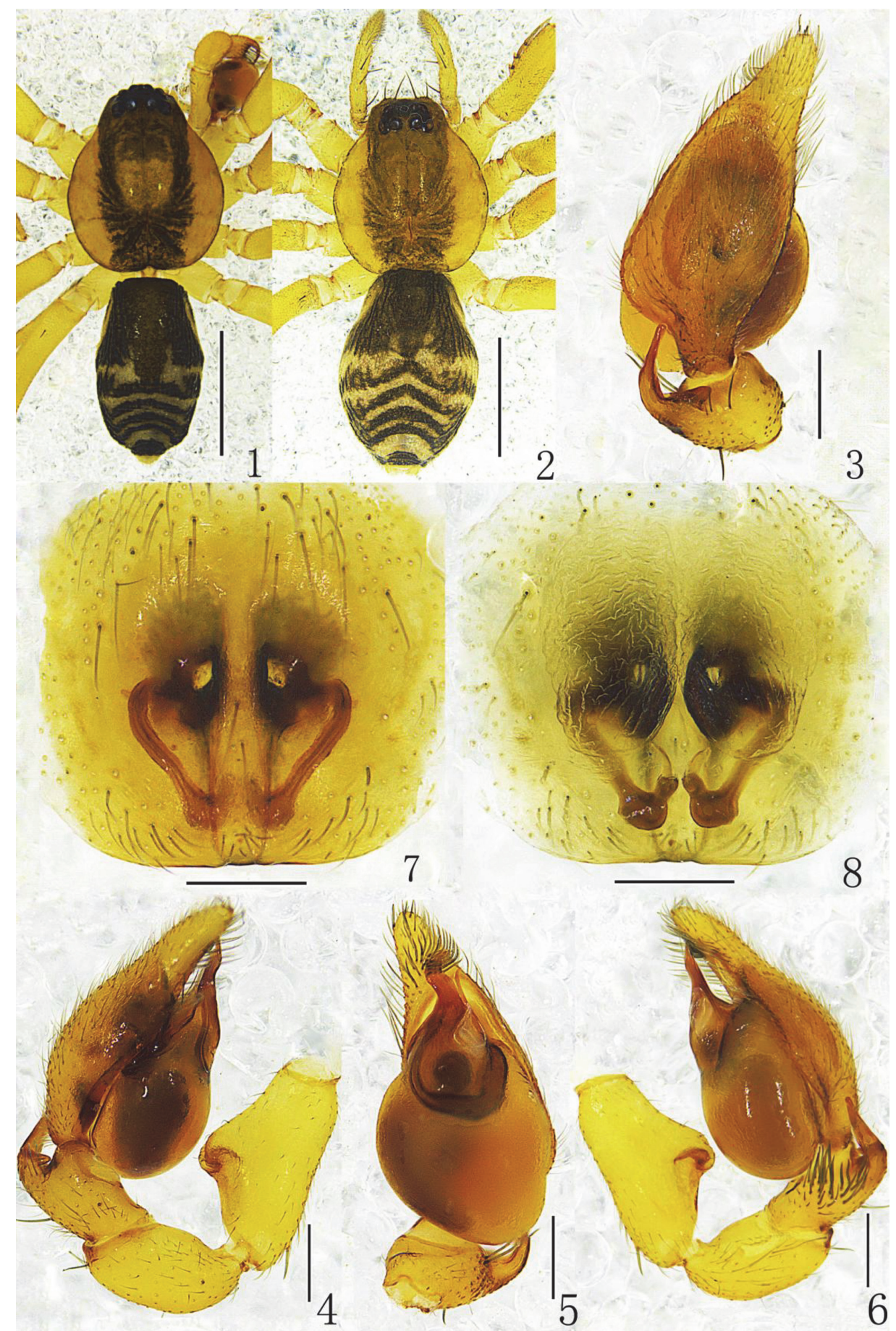



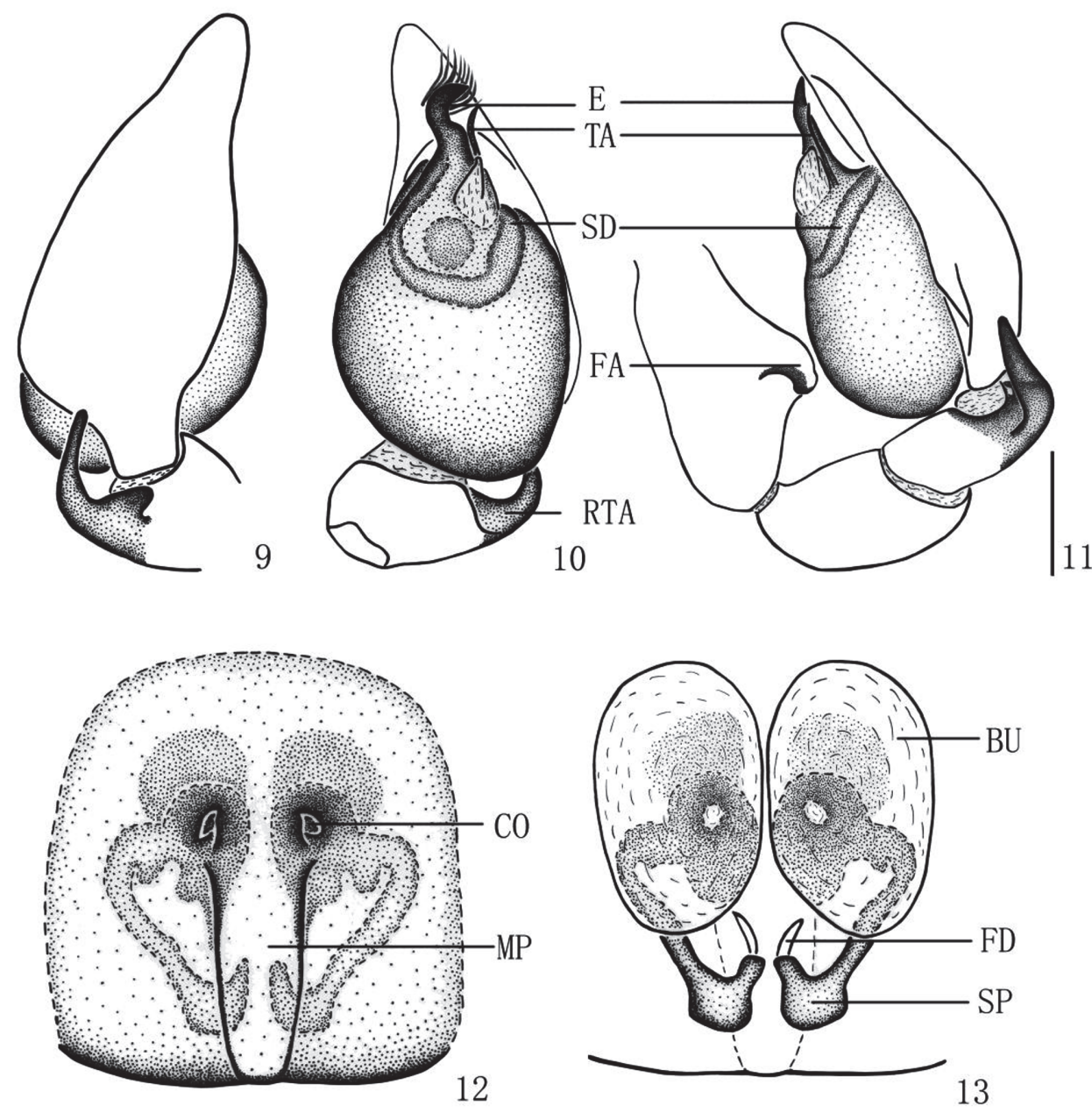

Figs 9-13. Otacilia obesa sp. n.: 9-11: left male palp: $9=$ dorsal view, $10=$ ventral view, $11=$ retrolateral view; 12 = epigyne, ventral view; 13 = vulva, dorsal view. Scale bars: $0.25 \mathrm{~mm}$ (9-11); $0.50 \mathrm{~mm}(12-13)$.

from Myanmar) by long and curve copulatory ducts (shorter in the latter), and narrow parallel lateral margin of median plate (broader in the latter). It is separated from O. christae Jäger et Wunderlich, 2012 and O. vangvieng Jäger et Wunderlich, 2012 (occurs in Laos) by hook-shaped embolus (not hook-shaped

Figs 1-8. Otacilia obesa sp. n.: 1= male habitus, dorsal view; 2 = female habitus, dorsal view; 3-6 = left male palp: $3=$ dorsal view, $4=$ prolateral view, $5=$ ventral view , $6=$ retrolateral view; 7 = epigyne, ventral view; $8=$ vulva, dorsal view. Scale bars: $1.00 \mathrm{~mm}(1-2) ; 0.20 \mathrm{~mm}(3-8)$. 
in the latter), and a long RTA (shorter in the latter); it is distinguished from O. bifurcata Dankittipakul et Singtripop, 2014 and O. truncata Dankittipakul et Singtripop, 2014 (occurs in Thailand) by long and thick embolus (shorter and sharper in the latter), single RTA (two different RTA in the latter), and presence of parallel epigynal median plate (absent epigynal median plate in the latter).

\section{Otacilia macrospora sp. $\mathrm{n}$.}

(Figs 14-26)

Type material. Holotype male, China, Anhui Province, Huangshan City, Lingnan Natural Reserve $\left(29^{\circ} 25.798^{\prime} \mathrm{N}, 118^{\circ} 12.415^{\prime} \mathrm{E}\right), 20$ October 2013 , Zhisheng Zhang leg. Paratypes: 2 males and 4 females, same data as holotype.

Etymology. The specific name is a combination of 'macros' and 'porus', referring to the large epigynal atrium.

Diagnosis. The new species is characterized by the following combination of characters: RTA thick with a small, flange-like extension located subapically; embolus crescent-shaped; TA sickle-shaped; sperm duct relatively long and curved; lateral margin of epigynal median plate parallel; atrium large, situated anteriorly; spermathecae small; copulatory duct long and bent; bursae small and oval, situated posteriorly; the posterior margin of epigynal plate with a notch.

Description - Male (Fig. 14). Total length 2.89-2.99 ( $\mathrm{n}=3$ ). Holotype: body 2.89 long; carapace 1.41 long, 1.22 wide; abdomen 1.35 long, 0.84 wide. Carapace oval, narrow anteriorly, yellowish, with broad median grey stripe; thoracic part higher than the cephalic part; fovea longitudinal, distinct. Diameter of eyes: AME 0.08, ALE 0.09, PME 0.07, PLE 0.06. Eye interdistances: AME-AME 0.06, AME-ALE 0.02, PME-PME 0.10, PME-PLE 0.07. MOA 0.25 long, front 0.19 wide, back 0.26 wide. Clypeus 0.11 high. Chelicerae light brown, with two bristles anteriorly; promargin of cheliceral furrow with three well-separated teeth and retromargin with five teeth. Labium and gnathocoxae brown. Legs and palps yellowish brown. Leg measurements: I 5.69 (1.48, 0.37, 1.74, 1.42, 0.68); II 4.70 (1.26, 0.47, 1.31, 1.08, 0. 58); III 4.13 (1.13, 0.44, 0.92, 1.09, 0.55); IV 5.98 (1.58, 0.43, 1.32, 1.79, 0.86). Leg formula: 4123. Femora I-IV with only one dorsal spine. Femora I with four prolateral spines and femora II with two prolateral spines; tibiae I with seven proventral spines and eight retroventral spines, tibiae II with seven pairs of ventral spines; metatarsi I with four pairs of ventral spines, metatarsi II with four proventral spines and three retroventral spines. Abdomen grey; anterior part without distinct scutum; posterior part dark brown, with several chevron-like stripes dorsally.

Figs 14-21. Otacilia macrospora sp. n.: $14=$ male habitus, dorsal view; $15=$ female habitus, dorsal view; 16-19 = left male palp: 16 = dorsal view, 17 = prolateral view, 18 = ventral view, 19 = retrolateral view; 20 = epigyne, ventral view; $21=$ vulva, dorsal view. Scale bars: 1.00 mm (14-15); 0.20 mm (16-21). 


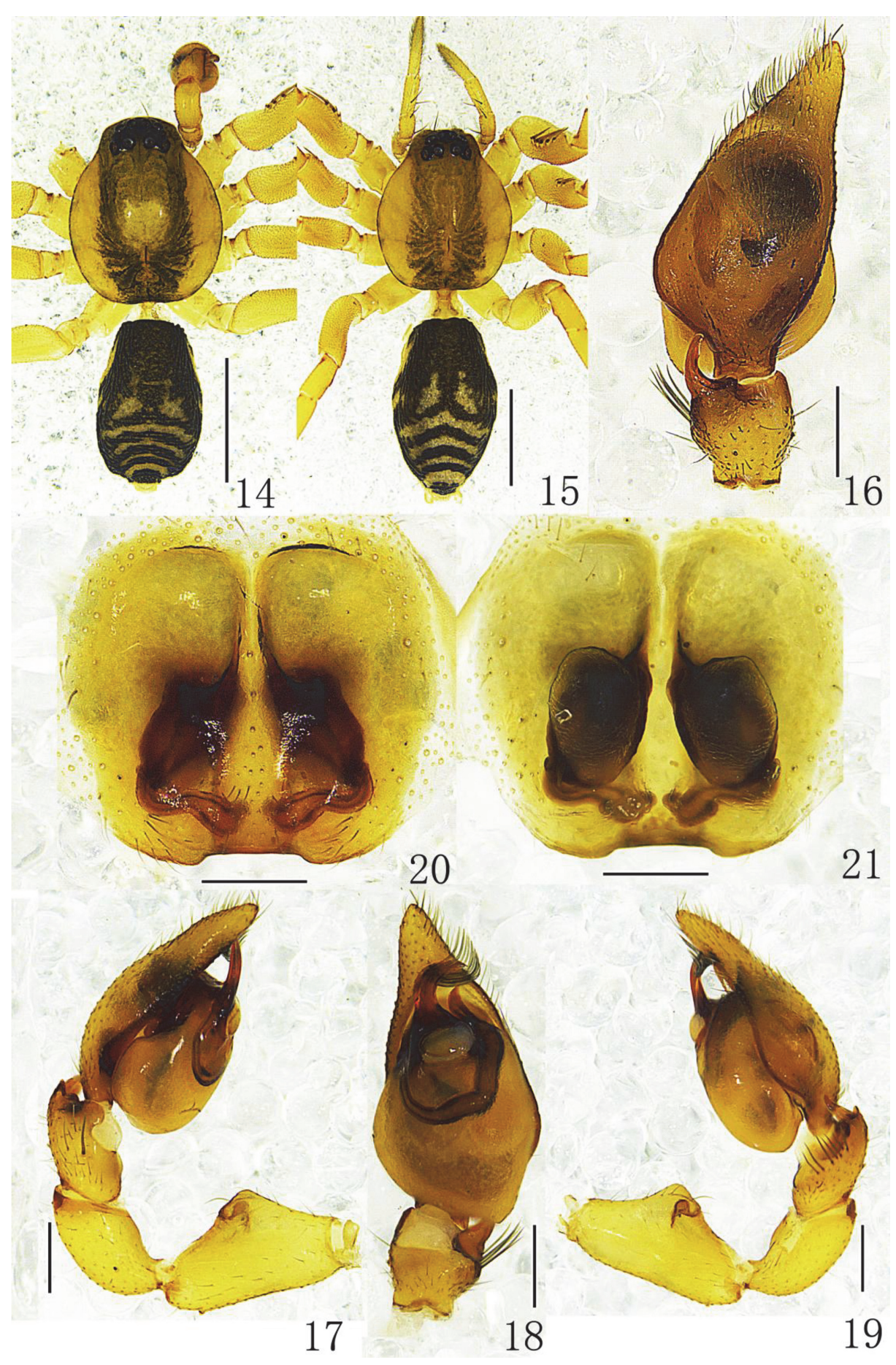


Palp (Figs 16-19, 22-24). Palpal femur with an median apophysis ventrally and a retrolateral concavity; RTA broad basally, pointed apically with a very small almost flangelike extension subapically; tibia distally with a row of long spines; tegular apophysis thick and short, sickle-shaped; embolus long and curved, crescent-shaped.

Female (Fig. 15). Total length 3.04-3.75 $(\mathrm{n}=4)$. One paratype: body 3.75 long; carapace 1.65 long, 1.40 wide; abdomen 1.87 long, 1.08 wide. Carapace brown, abruptly narrow anteriorly; fovea longitudinal. Diameter of eyes: AME 0.07, ALE 0.08, PME 0.08, PLE 0.07. Eye interdistances: AME-AME 0.06, AME-ALE 0.02, PME-PME 0.11, PME-PLE 0.06. MOA 0.26 long, front 0.20 wide, back 0.28 wide. Clypeus 0.09 high. Leg measurements: I
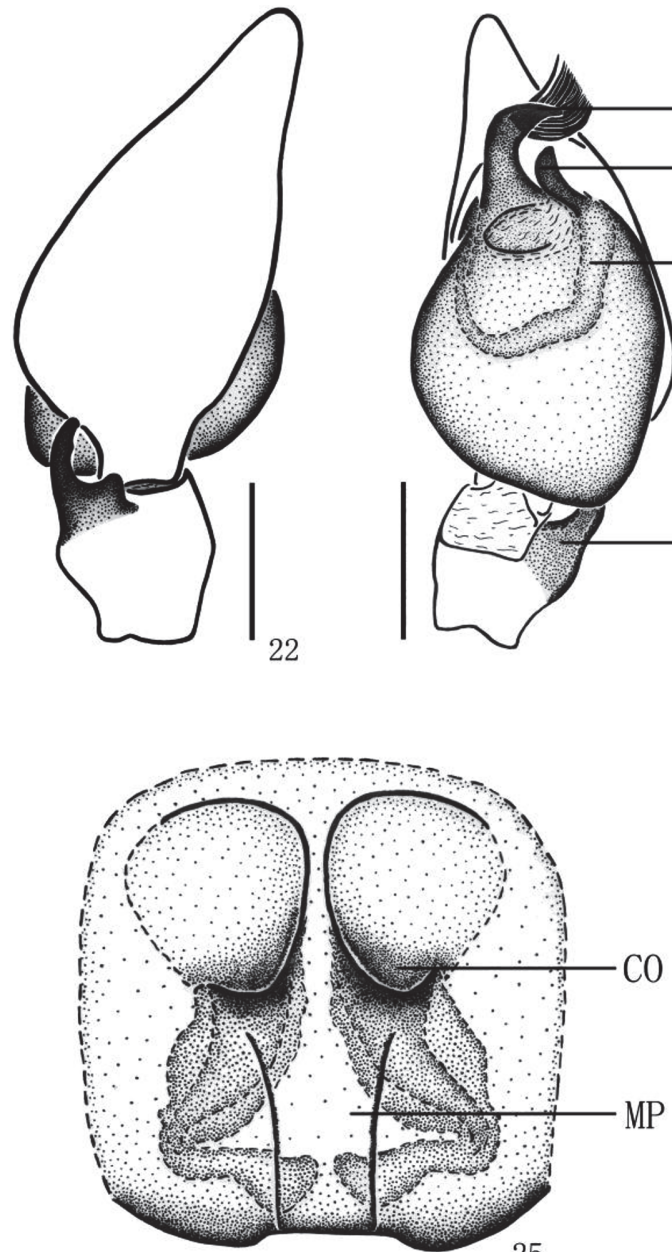

25

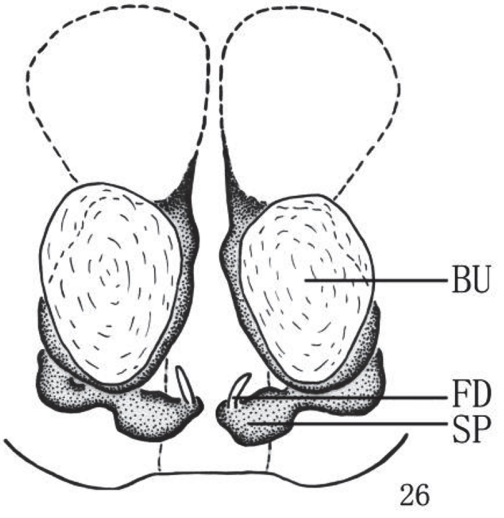

26

Figs 22-26. Otacilia macrospora sp. n.: 22-24: left male palp: $22=$ dorsal view, $23=$ ventral view , 24 = retrolateral view; 25 = epigyne, ventral view; 26 = vulva, dorsal view. Scale bars: $0.25 \mathrm{~mm}$ (22-24); $0.50 \mathrm{~mm}$ (25-26). 
$6.37(1.83,0.36,2.02,1.43,0.73)$; II 4.86 (1.52, 0.33, 1.47, 1.02, 0.52); III 3.78 (1.05, 0.27, 0.93, $0.91,0.62)$; IV $6.51(1.82,0.49,1.63,1.73,0.84)$. Leg formula: 4123. Femora I-IV with one dorsal spine. Femur I with five prolateral spines and femur II with three prolateral spines; tibiae and metatarsi I and II with the same spination as male. Abdomen grey dorsally. Other characters as in male.

Epigyne (Figs 20-21, 25-26): median plate rectangular, longer than wide, with parallel lateral margin; copulatory openings located in shallow atrium (Figs 20, 25). Vulva located posteriorly, with a pair of small, transparent egg-shaped bursae; spermathecae small sac-like, connecting with strongly curved copulatory ducts.

Distribution. China (Anhui).

Remarks. The new species O. macrospora resembles O. liupan, but can be distinguished from the latter by: 1) crescent-shaped embolus (hook-shaped in the latter); 2) thick and short TA (thinner and longer in the latter); 3) RTA with a smaller flange-like extension subapically (flange-like extension absent in the latter); 4) bursae loctaed posteriorly (anteriorly in the latter); 5) parallel lateral margin of median plate (not parallel lateral margin of median plate in the latter).

It also can be distinguished from other Otacilia species, such as, it differs from O. armatissima by longer copulatory ducts (short in the latter); it is separated from O. bicolor Jäger et Wunderlich, 2012 and O. namkhan Jäger et Wunderlich, 2012 (occur in Laos) by presence of median plate (median plate absent in the latter) and single RTA (two different RTA in the latter). It is also distinguished from O. vulpes (Kamura, 2001), O. stella Kamura, 2005 and O. mustela Kamura, 2008 (occur in Japan) by crescent-shaped embolus (not crescent-shaped in the latter).

As to the two new species in this paper, both of them have parallel lateral margin of epigynal median plate; however, the two species obviously differ from each other by the shapes of TA and RTA, the positions of COs and BU: $O$. macrospora with short and thick TA, while with slender TA in O. obesa; $O$. macrospora bearing thick RTA with a very small almost flange-like extension subapically, while without flange-like extension in the latter; O. macrospora with bursae posteriorly; while anteriorly in the latter.

Acknowledgements - Thanks to Mr. Luyu Wang (Southwest University, Chongqing, China) for collecting specimens. We are grateful to Dr Xinping Wang who kindly helped reviewing the manuscript. Jan Bosselaers and other anonymous reviewer are thanked for their comments that improved the manuscript. This work was supported by the National Natural Science Foundation of China (No. 31093430, 31372154), and in part by the Program of Ministry of Science and Technology of the Republic of China (2012FY110803) to Feng Zhang. 


\section{REFERENCES}

Banks, N. (1892) A classification of North American spiders. Canadian Entomologist 24: 88-97. http://dx.doi.org/10.4039/Ent2488-4

Dankittipakul, P. \& Singtripop, T. (2014). New species and new records of the spider genus Otacilia Thorell, 1897 (Araneae, Corinnidae) from Southeast Asia. Revue Suisse de Zoologie 121(3): 383-394.

Deeleman-Reinhold, C. L. (2001) Forest spiders of South East Asia: with a revision of the sac and ground spiders (Araneae: Clubionidae, Corinnidae, Liocranidae, Gnaphosidae, Prodidomidae and Trochanterriidae). Brill, Leiden, $591 \mathrm{pp}$.

Fu, J. Y., Zhang, F. \& Zhu, M. S. (2010) Three new species of the genus Otacilia (Araneae: Corinnidae) from Hainan Island, China. Journal of Natural History 44: 639-650. http:// dx.doi.org/10.1080/00222930903437341

Fu, L. N., Jin, C. \& Zhang, F. (2014). Three new species of the genus Otacilia Thorell (Araneae: Phrurolithidae) from China. Zootaxa 3869(4): 483-492. http://dx.doi.org/10.11646/ zootaxa.3869.4.10

Hu, D. S. \& Zhang, F. (2011) Description of a new Otacilia species from China, with transfer of two species from the genus Phrurolithus (Araneae: Corinnidae). Zootaxa 2993: 59-68.

Jäger, P. \& Wunderlich, J. (2012) Seven new species of the spider genus Otacilia (Araneae: Corinnidae) from China, Laos and Thailand. Beiträge zur Araneologie 7: 251-271.

Kamura, T. (2001) Seven species of the families Liocranidae and Corinnidae (Araneae) from Japan and Taiwan. Acta Arachnologica Tokyo 50: 49-61. http://dx.doi.org/10.2476/ asjaa. 50.49

Kamura, T. (2005) Spiders of the genus Otacilia (Araneae: Corinnidae) from Japan. Acta Arachnologica 53: 87-92. http://dx.doi.org/10.2476/asjaa.53.87

Kamura, T. (2008). A new species of the genus Otacilia (Araneae: Corinnidae) from Japan. Acta Arachnologica 57: 41-42. http://dx.doi.org/10.2476/asjaa.57.41

RAmírez, M. J. (2014) The morphology and phylogeny of dionychan spiders (Araneae: Arameomorphae). Bulletin of the American Museum of Natural History 390: 1-374. http:// dx.doi.org/10.1206/821.1

Song, D.X. (1990) On four new species of soil spiders (Arachnida: Araneae) from China. Journal of Hubei University (Natural Science) 12: 340-345.

Thorell, T. (1897) Viaggio di Leonardo Fea in Birmania e regioni vicine. LXXIII. Secondo saggio sui Ragni birmani. I. Parallelodontes. Tubitelariae. Annali del Museo Civico di Storia Naturali di Genova (2) 17: 161-267.

World Spider Catalog (2015) World Spider Catalog. Version 16. Natural History Museum Bern. http://wsc.nmbe.ch (accessed on 10 March 2015).

Yaginuma, T. (1952) Two new species (Phrurolithus and Ariamnes) found in Japan. Arachnological News 21: 13-16.

Received April 11, 2015, accepted July 28, 2015, published May 6, 2016 